\title{
AS CONTRIBUIÇÕES DA TEORIA CRÍTICA DOS DIREITOS HUMANOS DE HERRERA FLORES PARA A COMPREENSÃO DOS OBSTÁCULOS À EFICÁCIA DO SISTEMA INTERAMERICANO DE DIREITOS HUMANOS
}

\author{
THE CONTRIBUTIONS OF CRITICAL THEORY OF HUMAN RIGHTS OF \\ HERRERA FLORES FOR UNDERSTANDING OF OBSTACLES TO THE \\ EFFECTIVENESS OF THE INTER-AMERICAN HUMAN RIGHTS SYSTEM
}

\author{
${ }^{1}$ Felipe José Nunes Rocha \\ ${ }^{2}$ Monica Teresa Costa Sousa
}

\section{RESUMO}

$\mathrm{O}$ artigo analisa as contribuições da teoria crítica dos direitos humanos proposta por Herrera Flores para o estudo dos obstáculos à eficácia do Sistema Interamericano de Direitos Humanos. Após uma apresentação das críticas que o autor faz à teoria tradicional dos direitos humanos e das bases da sua teoria crítica, são feitas considerações sobre a formação do Sistema Interamericano de Direitos Humanos, seguida da apresentação de questões que evidenciam que os elementos da teoria de Herrera Flores, como a atenção voltada aos elementos contextuais inerentes aos direitos humanos, realmente favorecem a compreensão dos empecilhos que prejudicam o funcionamento daquele sistema.

Palavras-chave: Direitos humanos, Teoria crítica, Sistema interamericano de direitos humanos

\begin{abstract}
The article analyzes the contributions of critical theory of human rights proposed by Herrera Flores to study obstacles to the effectiveness of the Inter-American Human Rights System. After a presentation of the criticism that the author makes the traditional theory of human rights and of the basis of his critical theory, considerations are made about the formation of InterAmerican Human Rights System, followed by the presentation of issues that show that elements of Herrera Flores theory, as attention turned to contextual elements inherent to human rights, actually favor the understanding of the obstacles that hinder the functioning of that system.
\end{abstract}

Keywords: Human rights, Critical theory, Inter-american system of human rights

\footnotetext{
${ }^{1}$ Mestranda em Direito e Instituições do Sistema de Justiça pela Universidade Federal do Maranhão - UFMA, Maranhão (Brasil). Professor pela Faculdade Estácio de São Luis - FACSAOLUIS, Maranhão (Brasil).

E-mail: feliperocha7@gmail.com

${ }^{2}$ Doutora em Direito pela Universidade Federal de Santa Catarina - UFSC, Santa Catarina (Brasil). Professora pela Universidade Federal do Maranhão - UFMA, Maranhão (Brasil). E-mail: monicatcs@ yahoo.com
} 


\section{Introdução}

É notório o fato de que, por uma série de circunstâncias históricas, políticas, econômicas, sociais e culturais, não são raros os casos de violação a direitos humanos no Brasil que não recebem a resposta adequada por parte do Estado Brasileiro através dos instrumentos jurídicos e das instituições do sistema de justiça pátrios.

Diante disso, cada vez mais militantes e entidades que atuam na luta pela efetivação de direitos humanos têm recorrido ao Sistema Interamericano de Direitos Humanos (SIDH) para tentar resolver casos de violação que não são devidamente solucionados pelas instituições do Poder Judiciário e demais órgãos estatais brasileiros.

Entretanto, ainda é bastante discutível a efetividade dos tratados internacionais e das recomendações oriundas de organismos internacionais que integram o SIDH, por serem comuns as acusações no sentido de que os Estados que integram o sistema resistem a lhes dar cumprimento.

Assim, é de suma importância que se estude os motivos que fazem com que a existência de normas jurídicas, tratados internacionais e instituições voltadas para o monitoramento e para a implementação dos direitos humanos não seja suficiente para garantir a efetivação desses direitos no continente americano e no Brasil.

Um autor que muito contribuiu para a análise dessa "distância" entre a teoria e a prática dos direitos humanos foi Joaquín Herrera Flores. Ao longo de sua obra, ele desenvolveu uma teoria crítica dos direitos humanos que, além de demonstrar que a teoria tradicional constituiria, em si, um obstáculo para a plena efetivação de tais direitos, apresenta as bases para uma práxis voltada à superação de tais contingências.

Diante desse cenário, o presente artigo pretende analisar se e como a teoria crítica dos direitos humanos de Herrera Flores pode contribuir para a compreensão dos empecilhos que comprometem a eficácia do Sistema Interamericano de Direitos Humanos.

Para tanto, foi realizada uma pesquisa bibliográfica em obras que compõem o referencial teórico do trabalho e que fornecem os dados secundários analisados, bem como uma pesquisa documental em relatórios, decisões e outros documentos oriundos dos órgãos que compõem o Sistema Interamericano de Direitos Humanos e de órgãos do Poder Judiciário brasileiro.

Quanto à estrutura do trabalho, em um primeiro momento serão feitas considerações acerca da teoria crítica dos direitos humanos proposta por Joaquín Herrera Flores, tomando como base a sua obra "A (re)invenção dos direitos humanos" (2009a), que 
corresponde a um dos seus últimos livros, em que o autor sistematiza os elementos da teoria que elaborou ao longo de sua carreira acadêmica.

Então, serão feitas considerações acerca da formação do Sistema Interamericano de Direitos Humanos, seguidas da apresentação de questões concretas vivenciadas pela Comissão e pela Corte Interamericana de Direitos Humanos a partir das quais será possível verificar as relações existentes entre as bases da teoria crítica de Herrera Flores e os obstáculos à eficácia do referido sistema regional.

\title{
2. Considerações sobre a teoria crítica dos direitos humanos de Joaquín Herrera Flores
}

A teoria crítica proposta por Joaquín Herrera Flores (2009a) parte de uma contundente contestação à teoria tradicional dos direitos humanos, a qual se baseia na ideia de um universalismo abstrato que, além de ocultar o caráter ideológico de tais direitos, nega a importância dos contextos históricos, econômicos, sociais, políticos e culturais tanto no que diz respeito à teoria quanto à prática dos mesmos. Como afirma Herrera Flores:

\begin{abstract}
Por infelicidade, essa contextualização dos direitos não é algo que predomine nas análises e convenções internacionais a eles dirigidas. O contexto dos direitos não é visível. [...] Os direitos humanos, como geralmente todo fenômeno jurídico e político, estão permeados por interesses ideológicos e não podem ser entendidos à margem de seu fundo cultural e contextual (2009a, p.53 e 55).
\end{abstract}

Assim, a teoria tradicional reduz os direitos humanos a normas jurídicas formalmente inscritas em documentos internacionais ou nacionais, que todo ser humano possuiria desde o nascimento, ignorando que, na prática, é necessário que existam condições materiais para que as pessoas tenham acesso aos bens jurídicos tutelados por tais direitos. A esse respeito, aduz o autor:

\footnotetext{
Estamos diante de uma lógica bastante simplista que, contudo, tem consequências muito importantes, pois conduz a uma concepção "a priori" dos direitos humanos. Se estamos atentos, essa lógica nos faz pensar que temos os direitos mesmo antes de ter as capacidades e as condições adequadas para poder exercê-los. Desse modo, as pessoas que lutam por eles acabam desencantadas, pois, apesar de nos dizerem que temos direitos, a imensa maioria da população mundial não pode exercê-los por falta de condições materiais para isso. [...] No terreno dos direitos temos um grande paradoxo: a cada vez maior consolidação e proliferação de Textos Internacionais, Conferências Protocolos... em contraste, paralelamente, com o aprofundamento das desigualdades e injustiças que cada vez mais amplia a separação entre os polos, não só geográficos mas também econômicos e sociais, do Sul e do Norte. (HERRERA FLORES, 2009a, p.33 e 76)
}

$\mathrm{Na}$ verdade, por trás do manto da "neutralidade" e da "racionalidade", que os pensadores iluministas que conceberam a teoria tradicional dos direitos humanos utilizaram 
como fundamento para defender a ideia de direitos derivados da própria natureza humana, o que se percebe é que tanto essa teorização quanto a práxis dela decorrente “"[...] surgiram no Ocidente como resposta às reações sociais e filosóficas que pressupunham a consciência da expansão global de um novo modo de relação social baseada na constante acumulação de capital" (HERRERA FLORES, 2009a, p.42). Cenário esse que se agravou com o advento do capitalismo neoliberal ${ }^{1}$, aumentando ainda mais a distância entre a teoria e a prática dos direitos humanos (HERRERA FLORES, 2009a).

Outra importante crítica feita pelo autor à teoria tradicional dos direitos humanos diz respeito ao seu caráter etnocêntrico, haja vista que, como resultado do universalismo abstrato e "a priori” que ela defende, busca-se uma universalização dessa concepção de direitos humanos, que é um produto cultural da racionalidade moderna hegemônica nos países ocidentais - notadamente liberal e capitalista -, mesmo que muitos povos adotem e vivenciem outros processos de luta por dignidade humana distintos da concepção ocidental de direitos humanos $^{2}$. Daí porque o que se deve buscar é um "universalismo de chegada", que derive de um diálogo intercultural entre os diversos povos. Sobre o assunto, diz o autor:

\begin{abstract}
A partir da riqueza humana se rechaça qualquer universalismo a priori que imponha critérios como se fossem o padrão ouro da ideia de humanidade. O único universalismo que podemos defender desde essa posição é um universalismo a posteriori, um universalismo de chegada no qual todas as culturas possam oferecer suas opções e discuti-las em um plano, não de mera simetria, mas de igualdade. A partir dessa opção, a única definição que pode ser defendida é a que vê os direitos humanos como o sistema de objetos (valores, normas, instituições) e de ações (práticas sociais, institucionais ou não) que abram e consolidem espaços de lutas. (HERRERA FLORES, 2000, p. 264, tradução livre)
\end{abstract}

Feita esta breve exposição acerca das principais críticas de Herrera Flores à teoria tradicional dos direitos humanos, passa-se a abordar, também de maneira sucinta, as bases de sua teoria crítica.

Um primeiro ponto dessa teoria que merece destaque e que se relaciona com a refutação do autor a uma visão formal, abstrata e metafísica dos direitos humanos, é o fato dela não considerar que tais direitos correspondem exatamente aos bens que as normas jurídicas que os preveem visam assegurar, mas sim aos processos (jurídicos ou não) de luta por tais bens, os quais são diretamente influenciados pelos elementos contextuais de cada

\footnotetext{
1 “O sistema de valores hegemônicos em nossos dias é majoritariamente neoliberal e, por conseguinte, coloca por cima as liberdades funcionais ao mercado e por baixo as políticas públicas de igualdade social, econômica e cultural.” (HERRERA FLORES, 2009a, p.47)

2 "É possível dizer que o Ocidente não inventou a luta pela dignidade, mas formulou um discurso para dirigi-la em função de seus próprios interesses. Falamos dos direitos humanos do proprietário, branco e ocidental." (HERRERA FLORES, 2009a, p132)
} 
lugar e época e que têm, em comum, a característica de serem processos que objetivam alcançar o acesso aos bens necessários para uma vida com dignidade. Assim:

Como se vê, para nós, o conteúdo básico dos direitos humanos não é o direito a ter direitos (círculo fechado que não cumpriu com seus objetivos desde que se "declarou" há quase seis décadas). Para nós, o conteúdo básico dos direitos humanos será o conjunto de lutas pela dignidade, cujos resultados, se é que temos o poder necessário para isso, deverão ser garantidos por normas jurídicas, por políticas públicas e por uma economia aberta às exigências da dignidade. (HERRERA FLORES, 2009a, p.39)

Deve-se rejeitar, portanto, uma visão "purista" que negue a complexidade dos direitos humanos e os isole das condicionantes contextuais e conjunturais em que os processos de luta supramencionados se dão e que restrinja a discussão sobre tais direitos ao plano jurídico-normativo. Nas palavras do autor:

Por mais que uma norma (seja o código de trânsito, sejam os textos internacionais de direitos humanos) diga que "temos" os direitos, de pronto nos deparamos com a realidade, com os fatos concretos que vivemos, e o resultado definitivo pode ser bem diferente para uns e outros. Tudo dependerá da situação que cada um ocupe nos processos que facilitam ou dificultam o acesso aos bens materiais e imateriais exigíveis em cada contexto cultural para se alcançar a dignidade [...]

Nós pensamos que os fenômenos que acontecem em uma formação social determinada - entre eles, é claro, os direitos humanos - só podem ser entendidos no âmbito da soma dos processos sociais e econômicos que predominam num contexto espacial/temporal concreto. Todavia, também consideramos que podemos construir propostas normativas e realizar práticas sociais que possam ser usadas para transformar tais sistemas hegemônicos e propor a busca de alternativas reais e concretas, se é que percebemos que tais sistemas conduzem a injustiças e explorações do ser humano. (HERRERA FLORES, 2009a, p.44 e 93)

Esta é uma das mais importantes contribuições da teoria crítica dos direitos humanos para a compreensão dos obstáculos à eficácia dos sistemas internacionais de proteção aos direitos humanos, dentre os quais se encontra o Sistema Interamericano.

Com efeito, como será visto nos tópicos posteriores, há uma série de fatores contextuais metajurídicos que contribuem para que a existência de normas jurídicas e instituições nacionais e internacionais não seja suficiente para assegurar que tais sistemas atinjam os seus objetivos. O próprio Herrera Flores ilustra tal dificuldade ao discorrer sobre a Organização das Nações Unidas (ONU):

A história da ONU, por exemplo, está repleta de tentativas frustradas de controlar esses processos conducentes à desigualdade. Vejam-se a respeito os esforços da chamada UNCTAD (Conferência de Nações Unidas sobre Comércio e Desenvolvimento) para levar a cabo um Fundo Comum de Compensações que equilibre os intercâmbios comerciais entre o Norte o Sul, que restam obstaculizados sistematicamente por uma ordem global tendente a aprofundar as desigualdades e as injustiças. Para acrescentar outro exemplo, o trabalho de denúncia que se realiza anualmente através dos PNUD (Programas das Nações Unidas para o Desenvolvimento). (2009a, p. 99) 
Daí porque, como orienta o professor espanhol, ao se estudar, por exemplo, um tratado internacional, deve-se "analisar em que espaço social ele está situado, determinar qual é a conformação de maiorias e minorias que trabalham para o reconhecimento de suas formas particulares de relação social". Além do que, também se faz necessário "conhecer as diferentes posições de poder que os sujeitos ostentam em todo esse período" (HERRERA FLORES, 2009a, p.140).

Pode-se citar como exemplo da importância de se fazer uma análise que leve em consideração tais fatores o fato do governo de Cuba ter sido excluído do Sistema Interamericano de Direitos Humanos, no ano de $1962^{3}$, com base na alegação de que "a adesão de qualquer membro da Organização dos Estados Americanos ao marxismo-leninismo é incompatível com o Sistema Interamericano e o alinhamento de tal Governo com o bloco comunista afeta a unidade e solidariedade do hemisfério" (COMISSÃO INTERAMERICANA DE DIREITOS HUMANOS, 1996). Fato este que denota tanto a identificação da concepção de direitos humanos adotada pelo SIDH com a ideologia liberal capitalista do Ocidente, quanto que o referido sistema não "escapou ileso" do jogo de forças e das disputas políticas-ideológicas que marcaram o período da Guerra Fria.

Destaque-se, ainda, outra contribuição importante da teoria crítica para o Direito Internacional dos Direitos Humanos, que é a proposta de uma nova abordagem no tocante à tensão existente entre a visão abstrata dos direitos humanos, que tem a pretensão de estabelecer direitos universais, independentemente do fato de existirem culturas contrárias à concepção ocidental de direitos humanos, e a localista, que entende que, ante essa realidade multicultural, deve prevalecer a autonomia de cada povo, em detrimento das pretensões universalistas, em respeito às suas identidades culturais (HERRERA FLORES, 2009a).

Ao invés de aderir a uma dessas duas correntes, o professor espanhol rejeita tanto a racionalidade jurídico/formal da visão abstrata, que propõe práticas universalistas, quanto a racionalidade material/cultural inerente à visão localista, que propõe práticas particulares. Segundo Herrera Flores:

\footnotetext{
3 “A parte dispositiva da Resolução N ${ }^{\circ}$ VI da Oitava Reunião de Consulta de Ministros de Relações Exteriores da OEA estabelece que: 1. Que a adesão de qualquer membro da Organização dos Estados Americanos ao marxismo-leninismo é incompatível com o Sistema Interamericano e o alinhamento de tal Governo com o bloco comunista afeta a unidade e solidariedade do hemisfério. 2. Que o atual Governo de Cuba, que oficialmente identificou-se como um Governo marxista-leninista, é incompatível com os princípios e propósitos do Sistema Interamericano. 3. Que esta incompatibilidade exclui o atual Governo de Cuba de sua participação no Sistema Interamericano. 4. Que o Conselho da Organização dos Estados Americanos e outros órgãos do Sistema Interamericano adotem sem demora as providências necessárias para cumprir com esta Resolução." (COMISSÃO INTERAMERICANA DE DIREITOS HUMANOS, 1996)
} 
[...] as visões abstrata e localista possuem um problema em comum: o do contexto. Para a visão abstrata há uma falta absoluta de contexto, já que ela se desenvolve no vazio de um essencialismo perigoso, que não se considera como tal e se diz baseada em fatos e dados "da" realidade. Para a outra visão, há um excesso de contexto que, ao final, se desvanece no vazio que provoca a exclusão de outras perspectivas: outro essencialismo que somente aceita o que inclui, o que incorpora e o que valora; enquanto exclui e rechaça o que não coincide com ele. (2009a, p.158)

Em razão disso, ele apresenta uma "visão complexa" dos direitos humanos, que é fundada em uma "racionalidade de resistência" e que propõe uma prática intercultural. Tratase de uma "racionalidade que não nega que se possa chegar a uma síntese universal das diferentes opções ante os direitos e também não descarta a virtualidade das lutas pelo reconhecimento das diferenças étnicas e de gênero" (HERRERA FLORES, 2009a, p.163). O que tal proposta rejeita é a atitude de:

[...] considerar o universal como um ponto de partida ou um campo de desencontros. Ao universal, há que se chegar [...] depois [...] de um processo de luta discursivo, de diálogo ou de confrontação em que se rompam os preconceitos e as linhas paralelas (HERRERA FLORES, 2009a, p.163).

Considera-se tal questão de suma relevância para o estudo dos sistemas internacionais de proteção aos direitos humanos por diversos motivos. Em primeiro lugar, porque não são raros os casos que chegam às instâncias internacionais em que a questão do choque entre culturas se apresenta, a exemplo dos casos julgados pela Corte Interamericana de Direitos Humanos relativos a direitos de povos indígenas ${ }^{4}$.

Por outro lado, a visão proposta por Herrera Flores também ajuda a desvelar a complexidade e as contradições do cenário em que se dão as alianças internacionais que constituem a base desses sistemas, como se observa no seguinte fragmento da obra do autor:

\begin{abstract}
Não se pode acusar, por exemplo, os países não ocidentais de boicotar as conferências internacionais de direitos humanos do final do século XX por causa de suas culturas. No processo de todas essas reuniões, o Ocidente exige a inclusão de cláusulas de respeito ao livre comércio e às instituições dedicadas a impô-lo a todo mundo empobrecido, como se tais cláusulas fossem dogmas fechados que se situam fora do debate. Da mesma forma, também não se podem rechaçar todas as ideias ocidentais sobre direitos humanos como se todas elas fossem produto do colonialismo e do imperialismo. Negar "absolutamente" a visão ocidental dos direitos humanos conduz as culturas e países que o fazem a aceitar o fato de que a cultura ocidental é a única que os postula e defende, ou seja, o padrão-ouro a partir do qual identifica a luta pela dignidade humana. Essa pretensão de essencialismo étnico provoca o autodesprezo pela larga tradição não ocidental de luta pela dignidade. Tanto uma quanto outra posição partem de universalizações e de exclusões, não de processos que nos permitem chegar ao conjunto de generalidades que todos podemos compartilhar. (2009a, p.164-165)
\end{abstract}

\footnotetext{
${ }^{4}$ A título de exemplo, pode-se mencionar os casos da comunidade Mayagna (sumo) Awas Tingni vs. Nicarágua; Yatama Vs. Nicarágua; Povo Saramaka Vs. Suriname; Comunidade Indígena Xákmok Kásek Vs. Paraguai, dentre outros (BRASIL, 2014).
} 
Apresentados os principais elementos que compõem a teoria de Herrera Flores, passa-se a tecer considerações acerca do Sistema Interamericano de Direitos Humanos, que permitirão uma melhor visualização das contribuições que a teoria tem a dar para a compreensão dos obstáculos à eficácia de tal sistema.

\section{Os obstáculos à eficácia do Sistema Interamericano de Direitos Humanos}

Na IX Conferência Internacional Americana, realizada em 1948, em Bogotá, foram assinadas a Carta da Organização dos Estados Americanos (OEA), que entrou em vigor em 13 de dezembro de 1951 e que previu o respeito pelos direitos humanos como um de seus princípios, e a Declaração Americana dos Direitos e Deveres do Homem (HANASHIRO, 2001).

Posteriormente, em 1959, foi criada a Comissão Interamericana de Direitos Humanos, através da Quinta Reunião de Consulta de Ministros das Relações Exteriores, com o propósito de se estabelecer um mecanismo regional para tratar especificamente das violações de direitos humanos no âmbito do continente americano. Todavia, apenas em 1969 é que foi aprovado o principal instrumento de proteção aos direitos humanos na América Latina, que é a Convenção Americana de Direitos Humanos, também denominada Pacto de San José da Costa Rica (HANASHIRO, 2001).

Ainda assim, apenas a partir da década de 1980 é que o Sistema Interamericano de Direitos Humanos se fortaleceu. Em primeiro lugar, porque a Convenção Americana "só pôde entrar em vigor em 1978, quando o Governo de Granada depositou o $11^{\circ}$ instrumento de ratificação na Secretaria-geral da OEA” (HANASHIRO, 2001, p.31). Em segundo lugar porque, como explica Flávia Piovesan: "No caso latino-americano, o processo de democratização na região deflagrado na década de 80 é que propiciou a incorporação de importantes instrumentos internacionais de proteção dos direitos humanos” (2010, p.83).

Para garantir que os estados-membros cumpram os direitos que enuncia, a Convenção criou um aparato de monitoramento e implementação que abrange a Comissão Interamericana de Direitos Humanos e a Corte Interamericana de Direitos Humanos, as quais têm a competência de examinar casos de violações a direitos humanos denunciadas por indivíduos, grupos de indivíduos ou entidades, que não foram solucionadas pelos instrumentos de Direito interno dos respectivos países (HANASHIRO, 2001). 
A referida Corte, que corresponde ao órgão jurisdicional do sistema interamericano, composto por sete juízes oriundos de estados-membros da OEA, eleitos a título pessoal, possui uma competência consultiva e uma competência contenciosa (PIOVESAN, 2013).

A competência consultiva "[...] é o meio pelo qual esta responde a consultas e interpretações referentes à Convenção ou outro tratado de proteção aos Direitos Humanos, que são solicitadas pelos Estados membros da OEA e dos mesmos órgãos" (DUARTE; ANNONI, 2012, p.318).

Já a competência contenciosa corresponde ao poder da Corte Interamericana de julgar, através de sentença, os casos de violação a direitos humanos que lhes são encaminhados pela Comissão Interamericana. Sendo que, por força do disposto nos artigos 67 e 68 da Convenção Americana, "a decisão da Corte tem força jurídica vinculante e obrigatória, cabendo ao Estado seu imediato cumprimento" (PIOVESAN, 2013, p.214).

Frise-se que, para que um país possa ser submetido à jurisdição contenciosa da Corte Interamericana, é necessário que o mesmo reconheça expressamente a competência jurisdicional da Corte, o que, no caso do Brasil, ocorreu em 1998, através do Decreto Legislativo nº89, de 3 de dezembro de 1998 (ROSATO; CORREIA, 2011).

Por outro lado, também é útil enfatizar que, enquanto os processos judiciais que tramitam perante as instâncias domésticas produzem efeitos, em regra, apenas entre as partes litigantes, no âmbito do Sistema Interamericano de Direitos Humanos, é comum que o caso seja visto por uma perspectiva paradigmática, gerando consequências não só no sentido de reparação da violação perpetrada ou não repelida pelo Estado, mas também no sentido de evitar que novas violações semelhantes aconteçam, ultrapassando, assim, as partes envolvidas na lide (PIOVESAN, 2010).

Entretanto, apesar de ter havido significativos avanços oriundos da atuação da CIDH e da Corte IDH $^{5}$ em casos de violações a direitos humanos ocorridas no Brasil e em outros países da América, nota-se que elementos históricos, políticos, econômicos, sociais e culturais deste país e do continente americano comprometem sensivelmente a capacidade do

\footnotetext{
${ }^{5}$ A título de exemplo, pode-se mencionar o fato de que a sentença proferida pela Corte Interamericana no caso Ximenes Lopes Vs. Brasil já foi cumprida integralmente em relação a dez das doze medidas de reparação impostas na decisão e parcialmente em relação às duas restantes (de investigar os fatos em tempo razoável e estabelecer programas de capacitação para profissionais que atuam em saúde mental) (ROSATO; CORREIA,

2011). Do mesmo modo, convém mencionar algumas das contribuições oriundas de casos resolvidos pela Comissão Interamericana apontadas por Piovesan: “d) o Caso n.12.051[...], que resultou na condenação do Brasil por violência doméstica sofrida pela vítima, culminou na adoção da Lei n.11.340/2006 ("Lei Maria da Penha”) [...] f) os casos envolvendo violência rural e trabalho escravo contribuíram para a adoção do Programa Nacional de Erradicação do Trabalho Escravo. (2010, p.450-451);
} 
SIDH de contribuir para a efetivação desses direitos, evidenciando a importância de se adotar uma perspectiva crítica dos direitos humanos que reconheça a relevância de tais fatores para a sua eficácia, como a que propõe Joaquín Herrera Flores.

A esse respeito, um primeiro ponto a se observar é que, assim como ocorre no Sistema Global de proteção aos Direitos Humanos, no SIDH, o mecanismo de petições individuais somente é cabível em casos que versem sobre direitos civis e políticos ${ }^{6}$, de natureza individual, a partir do pressuposto de que tais direitos possuem aplicabilidade imediata, enquanto que os direitos econômicos, sociais e culturais seriam de realização progressiva (PIOVESAN, 2013).

Tal fato revela que tais sistemas têm como base a ideologia propagada pela teoria tradicional dos direitos humanos, que, embora defenda, em tese, a indivisibilidade dos direitos humanos, dá um tratamento prioritário aos direitos civis e políticos, em detrimento dos direitos econômicos sociais e culturais, cuja implementação corresponde às condições materiais necessárias para a efetivação plena de quaisquer direitos humanos, mostrando, assim, a presença da lógica liberal capitalista que encara tais direitos a partir de uma perspectiva individualista e jurídico-formal.

Com efeito, como os direitos econômicos, sociais e culturais demandam a discussão relativa aos elementos contextuais que são essenciais para a efetividade dos direitos humanos, não há como negar que a restrição do mecanismo de petições individuais - que é um dos principais instrumentos do sistema global e do SIDH de pressão sobre os Estados - aos direitos individuais denota uma opção política no sentido de impedir que a discussão relativa às condições materiais para a efetivação plena dos direitos humanos seja travada por instâncias internacionais como a Comissão e a Corte Interamericana de Direitos Humanos. Opção esta que, por sua vez, revela a intenção de não trazer à tona o fato de que é o próprio capitalismo neoliberal quem compromete sensivelmente a efetividade daqueles direitos.

Sobre o assunto, são bastante pertinentes as lições de Herrera Flores:

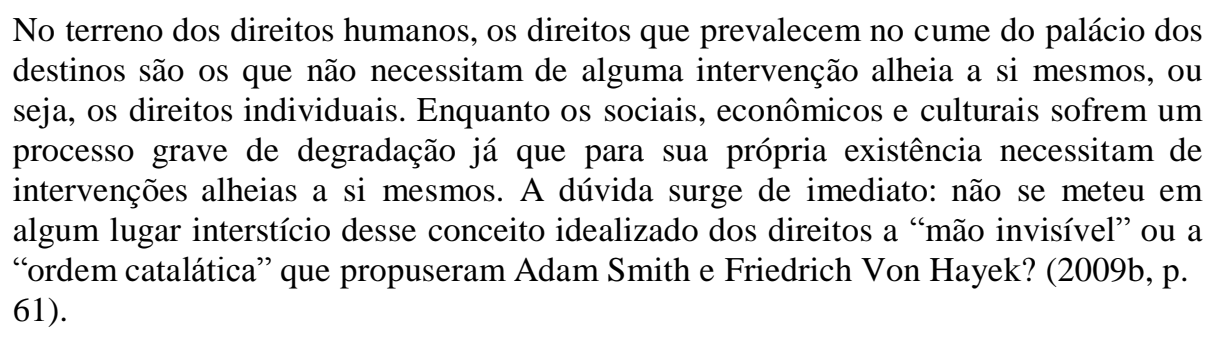

\footnotetext{
${ }^{6}$ A única exceção a exceção a essa regra são o direito à educação e à liberdade sindical, previstos no Protocolo de San Salvador, que, por força do art.19, item 6 do referido tratado internacional, podem ensejar a interposição de petições individuais perante a CIDH (PIOVESAN, 2013).
} 
Fora isso, uma análise crítica do Sistema Interamericano de Direitos Humanos também não pode ignorar questões geopolíticas importantes que marcam a História do continente, como, por exemplo, a intenção dos Estados Unidos da América de se estabelecer como "liderança" da região e de impor a sua ideologia aos países latino-americanos.

Uma pesquisa realizada por Maciel, Ferreira e Koerner (2013) acerca dos casos do SIDH que envolveram os EUA apresentou resultados bastante esclarecedores a respeito das questões acima mencionadas. Tal pesquisa foi realizada do seguinte modo:

[...] Identificamos o universo dos casos e dos denunciantes e traçamos o perfil tanto das iniciativas da CIDH e das respostas estatais norte-americanas quanto das formas e estratégias de mobilização adotadas pelos ativistas. Focalizamos, por um lado, a interação entre as instâncias governamentais e a autoridade regional e, por outro lado, a interação entre agentes estatais e não estatais com as decisões normativas de organizações internacionais. [...] A pesquisa analisou relatórios de casos contra os Estados Unidos desde o recebimento da primeira petição até 2011. O universo da pesquisa é constituído de 62 casos, coletados no sítio oficial da CIDH. Dentre as denúncias analisadas, 50 são de admissibilidade, 6 de inadmissibilidade e 4 de arquivamento. Para 2 casos, não obtivemos a informação.

(MACIEL; FERREIRA; KOERNER, 2013, p.272-273, 275)

Uma primeira observação relevante apontada pelos autores é o fato dos Estados Unidos terem assinado a Convenção Americana desde 1977, mas ainda não terem ratificado o referido tratado internacional, além de não terem se submetido à jurisdição contenciosa da Corte Interamericana de Direitos Humanos. Apesar disso, a partir de 1971, a Comissão Interamericana passou a receber petições individuais contra tal país a emitir recomendações a ele "com base na Carta da OEA, dado que esse instrumento incorporou a Declaração Americana dos Direitos e Deveres do Homem e instituiu a CIDH" (MACIEL; FERREIRA; KOERNER, 2013, p.275).

Dentre os temas que mais geraram denúncias contra os Estados Unidos, destacamse a pena de morte $(56,5 \%)$ e situações de imigração $(17,7 \%)$, sendo que, do total de denúncias formuladas, 80,6\% foram admitidas e, dentre as admitidas, 30,6\% receberam análise de mérito, resultando na responsabilização do país por todas ou por parte das violações alegadas pelos peticionários (MACIEL; FERREIRA; KOERNER, 2013).

Porém, é quando se analisa as reações do Departamento de Estado estadunidense às responsabilizações impostas pela $\mathrm{CIDH}$ que se torna patente o quanto a conjuntura geopolítica do continente americano interfere no funcionamento do SIDH. De fato, como explicam os autores:

Em todos os casos que tiveram o mérito analisado pela CIDH, as respostas norteamericanas alegam o não reconhecimento da validade das recomendações do órgão. Em contrapartida, o DE tem instado de forma recorrente a CIDH a analisar casos de violações de direitos humanos em outros Estados americanos e, ainda, tem se valido 
de relatórios da CIDH, como no caso do Panamá, para justificar a ação armada como defesa da democracia na região. [...]

Os Estados Unidos, a maior potência do Hemisfério Ocidental, ofereceram importante suporte político para a formação e a manutenção da OEA, bem como para a elaboração de mecanismos regionais de proteção dos direitos humanos. No entanto, é o país mais refratário à adesão ao SIPDH, ao não assinar tratados internacionais sobre a matéria. Ao mesmo tempo que são os principais financiadores da $\mathrm{CIDH}$ e incentivadores de relatórios de investigação de violações desses direitos na América Latina, os Estados Unidos não aceitam as recomendações e as medidas evocadas pela autoridade regional e é o Estado-membro que mais utiliza mecanismos próprios para descumprir as decisões da CIDH (Wilson, 2002).

(MACIEL; FERREIRA; KOERNER, 2013, p.282 e 290)

Ademais, cumpre salientar que a Suprema Corte estadunidense também já teve oportunidade de manifestar claro desprezo e resistência à atuação da CIDH em casos que envolvem violações a direitos humanos nos país, o que pode ser ilustrado pelo fato daquele tribunal ter aplicado a pena de morte a José Ernesto Medellin, muito embora a CIDH tenha expressamente requerido que os EUA adotassem as medidas necessárias para preservar a sua vida, até que a Comissão examinasse o mérito do caso daquele indivíduo (MACIEL; FERREIRA; KOERNER, 2013).

Assim, torna-se evidente que os processos históricos, econômicos e políticos ocorridos no continente americano, que resultaram em uma posição hegemônica dos EUA perante os demais países que integram o continente, marcam profundamente o funcionamento do SIDH, na medida em que servem de base para essa posição que reflete a doutrina do excepcionalismo estadunidense no âmbito do Direito Internacional dos Direitos Humanos, a qual se baseia em três elementos:

\footnotetext{
[...] (1) exemptionalism - o apoio a tratados, desde que os norte-americanos sejam imunes a eles; (2) double standards - criticam outros países por não seguirem as determinações dos corpos internacionais de direitos humanos, enquanto ignoram o que esses corpos discutem a respeito do próprio país e seus amigos, para os quais adotam apenas seus próprios critérios e julgamento; (3) legal isolationism - os tratados internacionais ratificados não se sobrepõem ao direito interno e os juízes do país tendem a ignorar outras normativas e jurisdições [...]. Este último aspecto pode ser observado na predominância da doutrina dualista no debate jurídico e nas decisões da Suprema Corte em casos de pena de morte [...].

(MACIEL, FERREIRA, KOERNER, 2013, p.282-283).
}

Ainda no tocante à influência dos elementos conjunturais do continente americano sobre o funcionamento do SIDH, é importante enfatizar que o fato anteriormente mencionado do governo cubano ter sido excluído do referido sistema em 1962 por ter adotado o regime socialista de inspiração marxista-leninista (COMISSÃO INTERAMERICANA DE DIREITOS HUMANOS, 1996) e de, em 2013, a Venezuela, cujo governo também se autoproclama socialista, ter apresentado um instrumento de denúncia da Convenção Americana de 
Direitos Humanos ${ }^{7}$ (COMISSÃO INTERAMERICANA DE DIREITOS HUMANOS, 2013), também evidenciam que, como bem ressalta Herrera Flores (2009a), o estudo acerca da eficácia de um sistema internacional de proteção aos direitos humanos exige uma abordagem que não se atenha apenas aos elementos jurídicos e institucionais que o compõem, mas que abranja também os elementos referentes ao contexto político, econômico, histórico, social e cultural a ele inerentes.

Para concluir, convém tecer algumas considerações sobre as dificuldades que têm sido encontradas para o cumprimento da sentença da Corte Interamericana de Direitos Humanos proferida no caso Gomes Lund e outros Vs. Brasil, para que se possa perceber que a abordagem proposta pela teoria crítica dos direitos humanos também tem muito a contribuir com a compreensão acerca dos obstáculos à eficácia do SIDH neste país.

Vale destacar que a sentença em questão foi escolhida como exemplo pelo fato dela ter imposto deveres ao Poder Judiciário brasileiro que têm sido sistematicamente descumpridos por magistrados e tribunais pátrios, sendo que o acesso dos autores aos documentos relativos ao caso tornou mais fácil a utilização do mesmo a título ilustrativo.

\section{Os obstáculos ao cumprimento dos deveres impostos ao Judiciário brasileiro pela sentença da Corte IDH que julgou o caso Gomes Lund e outros Vs. Brasil}

O caso em questão faz remissão a um dos eventos mais graves de violação de direitos humanos da Ditadura Militar brasileira, que foi a chamada "Guerrilha do Araguaia", em que 750 militares receberam ordens de executar sumariamente 71 guerrilheiros (MEYER, 2013).

Ante a ausência de informações acerca do paradeiro dos militantes desaparecidos na região, situada no estado do Pará, os familiares de 61 guerrilheiros procuraram o Poder Judiciário brasileiro, mas, por não obterem êxito, recorreram à Comissão Interamericana em 7 de agosto de 1995, através de entidades como o Centro pela Justiça e o Direito Internacional (CEJIL), o Human Rights Watch/Americas, o Grupo Tortura Nunca Mais do Rio de Janeiro e a

\footnotetext{
${ }^{7}$ Em documento emitido pelo Ministério del Poder Popular para la Comunicación y la Información, o governo venezuelano justificou a decisão de denunciar a Convenção Americana e de deixar de se submeter à jurisdição contenciosa da Corte Interamericana com base no argumento de que a Corte Interamericana estaria atuando em prol dos interesses dos Estados Unidos e de sua política de ingerência na América Latina. Além disso, também destacou o fato daquele país não se submeter à jurisdição contenciosa da Corte IDH e de a Comissão Interamericana ter sido o único organismo internacional que reconheceu Pedro Carmona Estanga (opositor que ocupou a presidência da Venezuela por poucos dias, em uma frustrada tentativa de golpe ocorrida em 2002) (VENEZUELA, 2013).
} 
Comissão de Familiares de Mortos e Desaparecidos Políticos do Instituto de Estudos da Violência do Estado da Universidade de São Paulo (MEYER, 2013).

Em 29 de março de 2009, a Comissão Interamericana submeteu o caso à Corte Interamericana de Direitos Humanos, que prolatou sentença em 24 de novembro de 2010 (MEYER, 2013). Na referida decisão, a Corte considerou que o Brasil violou vários dispositivos da Convenção Americana de Direitos Humanos e lhe impôs várias condenações, dentre as quais, encontram-se as seguintes:

[...] a) O Estado brasileiro deverá proceder a uma investigação judicial completa, efetiva e imparcial dos desaparecimentos forçados, identificando os responsáveis e sancionando-os criminalmente. A CteIDH estabeleceu que esses crimes são imprescritíveis e não podem ser objeto de anistias. Além disto, tais responsabilizações deverão acontecer no foro civil e não no foro militar. [...] (MEYER, 2013, p.222-223)

Ainda a respeito da referida condenação, também é importante salientar que, naquela sentença, a Corte Interamericana consignou expressamente que, apesar de o Supremo Tribunal Federal ter considerado que a Lei de Anistia (Lei no 6.683 de 1979) também serviria para anistiar os crimes praticados pelos militares no período da Ditadura Militar, tal entendimento não poderia constituir um óbice para que os militares responsáveis pelo desaparecimento forçado das vítimas da Guerrilha do Araguaia fossem processados e punidos, tendo em vista que tal interpretação da Lei de Anistia implicava na violação a vários compromissos internacionais assumidos pelo Brasil (CORTE INTERAMERICANA DE DIREITOS HUMANOS, 2010).

Por outro lado, a Corte também afastou o entendimento no sentido de que a punição dos crimes cometidos no período da Ditadura militar implicaria em violação ao princípio da irretroatividade da lei penal, por entender que o desaparecimento forçado é um delito que possui natureza contínua e permanente (CORTE INTERAMERICANA DE DIREITOS HUMANOS, 2010).

Com base em tais entendimentos, é que a Corte Interamericana, ao discorrer sobre o dever do Estado brasileiro de investigar e punir os crimes discutidos no caso Gomes Lund e outros Vs. Brasil, previu a obrigação do Brasil de:

[...] determinar os autores materiais e intelectuais do desaparecimento forçado das vítimas e da execução extrajudicial. Ademais, por se tratar de violações graves de direitos humanos, e considerando a natureza dos fatos e o caráter continuado ou permanente do desaparecimento forçado, o Estado não poderá aplicar a Lei de Anistia em benefício dos autores, bem como nenhuma outra disposição análoga, prescrição, irretroatividade da lei penal, coisa julgada, ne bis in idem ou qualquer excludente similar de responsabilidade para eximir-se dessa obrigação [...]. (CORTE INTERAMERICANA DE DIREITOS HUMANOS, 2010, p.96) 
Entretanto, embora o MPF tenha desempenhado um papel muito importante para dar cumprimento à sentença, promovendo uma série de denúncias contra militares que praticaram crimes no período da Ditadura Militar, o que se observa é que o Poder Judiciário brasileiro tem manifestado uma grande resistência em acatar o que restou decidido pela Corte.

No presente trabalho, serão analisadas apenas as três denúncias ofertadas pelo MPF (MARX, 2015) que versam sobre crimes cometidos na Guerrilha do Araguaia, por serem as que se relacionam mais diretamente com os fatos discutidos no caso Gomes Lund e outros Vs. Brasil.

Quanto à primeira denúncia, feita contra Sebastião Curió Rodrigues de Moura na Justiça Federal de Marabá-PA, é útil apresentar a síntese do seu desfecho feita por Marx, nos termos seguintes:

[...] A defesa do acusado, em 30/10/2012, impetrou o Habeas Corpus $n^{\circ} 0068063$ 92.2012.4.01.0000, junto ao TRF da $1^{a}$ Região, objetivando o trancamento da ação penal. Medida liminar determinando a suspensão do processo até o juízo final de mérito do Habeas Corpus foi concedida em 19 de novembro. Em 18 de novembro de 2013, a $4^{\text {a }}$ Turma do TRF da $1^{\text {a }}$ Região, por maioria, concedeu ordem para trancar a ação penal. O MPF ingressou com embargos de declaração, rejeitados em 15 de julho de 2014. Recursos especial e extraordinário foram interpostos pelo MPF. (2015, p.460-461)

Na segunda denúncia (Processo $n^{\circ}$ 0004334-29.2012.4.01.3901 ${ }^{8}$ ), oferecida em 16 de julho de 2012, o MPF denunciou Lício Augusto Maciel por sequestro qualificado por maus-tratos em razão do desparecimento forçado de Divino Ferreira de Souza, ocorrido em 14 de outubro de 1973 (MARX, 2015).

A referida denúncia teve andamento bastante semelhante à primeira: foi recebida em primeira instância, mas, após o ajuizamento de habeas corpus pelo acusado (Processo $\mathrm{n}^{\circ}$ 0066237-94.2013.4.01.0000), foi concedida liminar (BRASIL, 2016b) determinando o trancamento da ação penal pelo mesmo desembargador do Tribunal Regional Federal da $1^{\mathrm{a}}$ Região, através de decisão com idêntico teor ao da que foi prolatada no caso de Sebastião Curió (BRASIL, 2016b), estando ambos os casos aguardando julgamento do Superior Tribunal de Justiça e do Supremo Tribunal Federal.

Com efeito, em ambas as situações o desembargador federal Olindo Menezes determinou liminarmente o trancamento das ações penais, por considerar que a sentença do caso Gomes Lund e outros Vs. Brasil não prevaleceria sobre o entendimento do STF no

\footnotetext{
${ }^{8}$ Após o recebimento da denúncia, a ação penal adquiriu o número 0006232-77.2012.4.01.3901 (BRASIL, 2016a).
} 
sentido de que a Lei de Anistia também se aplicaria sobre os crimes praticados pelos militares na época da ditadura militar (BRASIL, 2016b).

Vê-se, portanto, que embora aquele magistrado tivesse ciência da sentença da Corte Interamericana, descumpriu deliberadamente a parte da decisão que aduz que "o Estado não poderá aplicar a Lei de Anistia em benefício dos autores, bem como nenhuma outra disposição análoga, prescrição, irretroatividade da lei penal, coisa julgada, ne bis in idem" (CORTE INTERAMERICANA DE DIREITOS HUMANOS, 2010, p.96), em claro desrespeito à autoridade daquele tribunal internacional.

Aliás, a própria Corte IDH, em uma resolução relativa à supervisão do cumprimento da sentença, de outubro de 2014, manifesta a sua reprovação à conduta do Judiciário brasileiro de descumprir a decisão, ao se pronunciar sobre o Processo nº068063-

92.2012.4.01.0000, como se vê nas seguintes passagens daquele documento:

\begin{abstract}
[...] De acordo com o Direito Internacional, que foi soberanamente aceito pelo Estado, é inaceitável que uma vez que a Corte Interamericana tenha proferido uma Sentença o direito interno ou suas autoridades pretendam deixá-la sem efeitos. Portanto, o Brasil não pode opor decisões adotadas no âmbito interno como justificativa de seu descumprimento da sentença proferida por este tribunal internacional de direitos humanos, nem sequer quando tais decisões provenham do tribunal da mais alta hierarquia no ordenamento jurídico nacional. Independentemente das interpretações que se realizem no âmbito interno, a Sentença proferida pela Corte Interamericana neste caso tem caráter de coisa julgada internacional e é vinculante em sua totalidade. Portanto, resulta contrário às obrigações convencionais do Brasil que se interprete e aplique no âmbito interno a Lei de Anistia desconhecendo o caráter vinculante da decisão já proferida por este Tribunal.

(CORTE INTERAMERICANA DE DIREITOS HUMANOS, 2014, p.10-12, sem grifos no original)
\end{abstract}

Mas, ao invés do Estado brasileiro mudar de postura após a Corte Interamericana ter chamado a sua atenção para a necessidade de as decisões judiciais se adequarem ao entendimento consagrado na sentença que julgou o caso Gomes Lund e outros Vs. Brasil, verifica-se que a resistência acima demonstrada persistiu, o que pode ser comprovado pelo fato da terceira denúncia do MPF relativa a crimes da Guerrilha do Araguaia, oferecida em 28 de janeiro de 2015, não ter sido recebida pelo juiz federal de primeira instância da subseção judiciária de Marabá-PA (BRASIL, 2016c).

Assim, o que se verifica é que, ao invés de perceberem a Corte Interamericana de Direitos Humanos como uma instância jurisdicional cuja autoridade deve prevalecer sobre a das instituições do sistema de justiça domésticas - inclusive sobre a do Supremo Tribunal Federal -, os magistrados brasileiros têm desobedecido deliberadamente os deveres jurídicos que lhes foram impostos pela sentença de Corte Interamericana por entenderem que a decisão 
do STF deve prevalecer sobre a daquele tribunal internacional, comprometendo sensivelmente a efetividade do sistema interamericano de direitos humanos.

Por outro lado, o fato de, até o momento, o Supremo Tribunal Federal não ter julgado os Embargos de Declaração opostos pelo Conselho Federal da OAB nos autos da ADPF $\mathrm{n}^{\circ} 153$ com o intuito de provocar aquele tribunal a se pronunciar sobre as determinações contidas na sentença do caso Gomes Lund e outros Vs. Brasil, em que pese a veemência com que a Corte IDH reiterou, ainda em outubro de 2014, o dever do Estado brasileiro de cumprir a sentença e de modificar a interpretação que foi conferida à Lei de Anistia (CORTE INTERAMERICANA DE DIREITOS HUMANOS, 2014), traz à tona possíveis (ou prováveis) fatores metajurídicos que prejudicam o funcionamento adequado do Sistema Interamericano no Brasil.

A título de exemplo, pode-se mencionar a deficiência na comunicação entre as instituições do Poder Executivo que recebem as determinações da Corte e os órgãos do Poder Judiciário responsáveis por dar cumprimento a elas, a qual pode derivar de uma histórica ausência (ou deficiência) de diálogo institucional entre os três poderes.

Além disso, o fato de o STF se sentir tão "à vontade" para não tratar a questão como algo urgente, a despeito da contundência das críticas da Corte, e não incluir em pauta o recurso que irá ensejar uma nova discussão sobre a matéria também pode advir de uma cultura marcada por um excessivo grau de discricionariedade dos tribunais brasileiros quanto às matérias que devem ser postas em pauta, pela ausência de um controle social que pressione as instâncias judiciais a debater sobre assuntos de tamanha relevância, bem como pelo fato da magistratura brasileira não encarar a questão da Justiça de Transição, como algo relevante e urgente ante as estreitas e históricas relações existentes entre os membros do Judiciário e as elites do país.

\section{Considerações finais}

Embora tenha sido superficial a análise dos obstáculos à eficácia do Sistema Interamericano de Direitos Humanos realizada no presente artigo, os elementos apresentados no tópico anterior são suficientes para demonstrar que a visão tradicional dos direitos humanos, criticada por Joaquín Herrera Flores, esteve presente na formação do SIDH e é insuficiente para a compreensão desses empecilhos.

Por outro lado, também foi possível perceber que, ao propor uma visão complexa dos direitos humanos, que os conceba como produtos culturais resultantes de processos de 
luta que são influenciados por fatores contextuais de diversas ordens, não se restringindo aos aspectos jurídico-formais e institucionais, a teoria crítica dos direitos humanos de Herrera Flores fornece bases importantes para o estudo das vicissitudes que impedem que o SIDH cumpra adequadamente a sua função de prevenir e repreender as violações a direitos humanos ocorridas no continente americano.

De fato, os obstáculos examinados neste artigo demandam o exame de questões históricas, políticas, econômicas, sociais e culturais importantes que dizem respeito às relações entre os países que compõem o continente americano, às questões históricas relacionadas ao surgimento e à formação do SIDH e a elementos inerentes à cultura institucional de órgãos internos de cada país. Torna-se, portanto, patente a insuficiência e a incompletude de uma análise que se restrinja aos elementos normativos e institucionais relativos ao sistema.

Somente com a superação desse olhar simplista sobre uma realidade tão complexa é que será possível identificar quais são as mudanças efetivamente necessárias para o aprimoramento da eficácia do SIDH e para uma efetivação mais plena dos direitos humanos no continente americano e no Brasil.

\section{REFERÊNCIAS}

BRASIL. Jurisprudência da Corte Interamericana de Direitos Humanos / Secretaria Nacional de Justiça, Comissão de Anistia, Corte Interamericana de Direitos Humanos. Tradução da Corte Interamericana de Direitos Humanos. Brasília: Ministério da Justiça, 2014. Disponível em: $\quad<$ http://www.sdh.gov.br/assuntos/atuacao-internacional/sentencas-da-corteinteramericana/pdf/direitos-dos-povos-indigenas>. Acesso em 26 mar. 2016.

\section{Tribunal Regional Federal da $1^{\text {a }}$ Região. Habeas corpus $\mathbf{n}^{\mathbf{0}} \mathbf{0 0 6 6 2 3 7 -}$}

94.2013.4.01.0000. Impetrante: Rodrigo Henrique Roca Pires. Impetrado: Juiz federal da $2^{\mathrm{a}}$ vara da subseção judiciária de Marabá - PA. Paciente: Lício Augusto Maciel. Relator: Olindo de Menezes. Brasília, 5 de novembro de 2013. Disponível em: <www.stj.jus.br〉. Acesso em: 22 mar. 2016a.

Tribunal Regional Federal da $1^{\mathrm{a}}$ Região. Habeas corpus $\mathbf{n}^{\mathbf{0}}$ 006806392.2012.4.01.0000. Impetrante: Mário Gilberto de Oliveira. Impetrado: Juiz federal da $1^{\mathrm{a}}$ vara da subseção judiciária de Marabá - PA. Paciente: Sebastião Curió Rodrigues de Moura. Relator: Olindo de Menezes. Brasília, 30 de outubro de 2012. Disponível em: <www.stj.jus.br>. Acesso em: 22 mar. 2016b.

$1^{a}$ Vara Federal da Subseção judiciária de Marabá-PA. Denúncia no $0000342-$ 55.2015.4.01.3901. Autor: Ministério Público Federal. Réus: Sebastião Curió Rodrigues de Moura e Lício Augusto Ribeiro Maciel. Juiz federal: Marcelo Honorato. Brasília, 29 de janeiro de 2015. Disponível em: <www.trf1.jus.br>. Acesso em: 23 mar. 2016c. 
COMISSÃO INTERAMERICANA DE DIREITOS HUMANOS. Relatório Anual de 1996. Capítulo V: Desenvolvimento dos Direitos Humanos na região. Cuba. Disponível em: < https://cidh.oas.org/annualrep/96port/96PortCap5.1.htm\#CUBA>. Acesso em 26 mar. 2016.

CORTE INTERAMERICANA DE DIREITOS HUMANOS. Caso Gomes Lund e outros ("Guerrilha do Araguaia") Versus Brasil: sentença de 24 de novembro de 2010. Disponível em: <www.corteidh.or.cr/docs/casos/articulos/seriec_219_por.pdf〉. Acesso em 22 mar. 2016.

Resolução da Corte Interamericana de Direitos Humanos de 17 de

outubro de 2014. Caso Gomes Lund e outros ("Guerrilha do Araguaia") Vs. Brasil: Supervisão de cumprimento de sentença. Disponível em: <www.corteidh.or.cr/docs/supervisiones/gomes_17_10_14_por.pdf >. Acesso em 23 mar. 2016.

Relatório Anual de 2013. Disponível em:

<http://www.corteidh.or.cr/tablas/informe2013/portugues.pdf〉. Acesso em 26 mar. 2016.

DUARTE, Mônica; ANNONI, Danielle. A eficácia das sentenças da Corte Interamericana no Sistema Jurídico Brasileiro. In: ANNONI, Danielle (org.). Direito Internacional dos Direitos Humanos: Homenagem à Convenção Americana de Direitos Humanos. São Paulo: Conceito Editorial, 2012.

HANASHIRO, Olaya Sílvia Machado Portella. O Sistema Interamericano de Proteção aos Direitos Humanos. São Paulo: Editora da Universidade de São Paulo, 2001.

HERRERA FLORES, Joaquín. A reinvenção dos direitos humanos. Florianópolis: Boiteux, 2009a.

Teoria crítica dos direitos humanos: os direitos humanos como produtos culturais. Rio de Janeiro: Lumen Juris, 2009b.

. El vuelo de Anteo: Derechos humanos y crítica de la razón liberal. Bilbao:

Desclée De Brouwer, 2000.

MACIEL, Débora Alves; FERREIRA, Marriele Maia Alves; KOERNER, Andrei. Os Estados Unidos e os mecanismos regionais de proteção dos direitos humanos. In: Lua Nova. Revista de Cultura e Política, São Paulo, n. 90, p.271-295, 2013.

Disponível em: <http://www.scielo.br/pdf/ln/n90/a10n90.pdf>. Acesso em: 25 mar. 2016.

MARX, Ivan Cláudio. Atuação do Ministério Público Federal na Justiça Transicional brasileira. In: SOUSA JUNIOR, José Geraldo de. et. al. (orgs.). O direito achado na rua: introdução crítica à justiça de transição na América Latina. v.7. 1. ed. Brasília: UnB, 2015. Disponível em: <http://www.justica.gov.br/central-de-conteudo/anistia/anexos/15-12-15direito-achado-na-rua-vol-7_web-versao-10mb-1.pdf>. Acesso em 22 dez. 2015.

MEYER, Emílio Peluso Neder. Responsabilização por graves violações de direitos humanos na ditadura de 1964-1985: a necessária superação da decisão do Supremo Tribunal Federal na ADPF ${ }^{\circ}$ 153/DF pelo Direito Internacional dos Direitos Humanos. Tese de Doutorado. Belo Horizonte: UFMG, 2013. Disponível em:

https://www.ufmg.br/online/arquivos/anexos/emilio_peluso_neder_meyer.pdf> Acesso em: 
22 dez. 2015.

PIOVESAN, Flávia. Temas de Direitos Humanos. 4 ed. São Paulo: Saraiva, 2010.

. Direitos humanos e o Direito Constitucional Internacional. 14.ed. rev. e atual. São Paulo: Saraiva, 2013.

ROSATO, Cássia Maria; CORREIA, Ludmila Cerqueira. Caso Damião Ximenes Lopes: Mudanças e Desafios após a primeira condenação do Brasil pela Corte Interamericana de Direitos Humanos. Sur - Revista Internacional de Direitos Humanos, São Paulo, v. 8, n. 15, p. 93-114, dez.2011.

VENEZUELA. Denuncia y Salida de Venezuela de la Corte Interamericana de Derechos Humanos. Disponível em:

<http://www.minci.gob.ve/wpcontent/uploads/downloads/2013/09/DISCURSO-CIDH-20-913-web.pdf>. Acesso: 26 mar. 2016. 